\title{
Resveratrol protects against asthma-induced airway inflammation and remodeling by inhibiting the HMGB1/TLR4/NF-kB pathway
}

\author{
HUANHUAN JIANG, JUNYAN DUAN, KAIHONG XU and WENBO ZHANG \\ Department of Pediatrics, The Affiliated Changzhou No. 2 People's Hospital of Nanjing Medical University, \\ Changzhou, Jiangsu 213000, P.R. China
}

Received August 13, 2018; Accepted March 29, 2019

DOI: $10.3892 /$ etm.2019.7594

\begin{abstract}
The aim of the present study was to explore the protective role of resveratrol (RES) in asthma-induced airway inflammation and remodeling, as well as its underlying mechanism. An asthma rat model was induced by ovalbumin (OVA) treatment. Rats were randomly assigned into sham, asthma, $10 \mu \mathrm{mol} / 1 \mathrm{RES}$ and $50 \mu \mathrm{mol} / 1 \mathrm{RES}$ groups. The amount of inflammatory cells in rat bronchoalveolar lavage fluid (BALF) was detected. Pathological lesions in lung tissues were accessed by hematoxylin and eosin (H\&E), and Masson's trichrome staining. Levels of inflammatory factors in lung homogenate were detected via ELISA. The blood serum of asthmatic and healthy children was also collected for analysis. Reverse transcription-quantitative polymerase chain reaction was performed to detect high mobility group box 1 (HMGB1), Toll-like receptor 4 (TLR4), myeloid differentiation primary response gene $88(\mathrm{MyD} 88)$ and $\mathrm{NF}-\kappa \mathrm{B}$ expression in asthmatic and healthy children, as well as rats of the different groups. H\&E staining demonstrated that multiple inflammatory cell infiltration into the rat airway epithelium of the asthma group occurred whilst the $50 \mu \mathrm{mol} / 1$ RES group displayed alleviated pathological lesions. Masson staining indicated that there was an increased airway collagen deposition area in the asthma and $10 \mu \mathrm{mol} / 1 \mathrm{RES}$ groups compared with the $50 \mu \mathrm{mol} / 1 \mathrm{RES}$ group. The number of inflammatory cells in BALF extracted from rats of the asthma and $10 \mu \mathrm{mol} / 1 \mathrm{RES}$ groups was higher compared with the $50 \mu \mathrm{mol} / 1 \mathrm{RES}$ group. Treatment with $50 \mu \mathrm{mol} / \mathrm{l}$ RES significantly decreased the thicknesses of the airway wall and smooth muscle. ELISA results illustrated that interleukin (IL)-1, IL-10 and tumor necrosis factor- $\alpha$ (TNF- $\alpha$ ) levels were elevated, whereas IL-12 level was reduced in lung tissues of the asthma and $10 \mu \mathrm{mol} / 1 \mathrm{RES}$ groups whilst
\end{abstract}

Correspondence to: Dr Wenbo Zhang, Department of Pediatrics, The Affiliated Changzhou No. 2 People's Hospital of Nanjing Medical University, 29 Xinglong Lane, Changzhou, Jiangsu 213000, P.R. China

E-mail: rpsf14@163.com

Key words: asthma, inflammatory response, high mobility group box $1 /$ Toll-like receptor $4 / \mathrm{NF}-\kappa \mathrm{B}$, resveratrol the $50 \mu \mathrm{mol} / 1 \mathrm{RES}$ group demonstrated the opposite trend. HMGB1, TLR4, MyD88 and NF- $\kappa$ B mRNA levels were remarkably elevated in rats of the asthma and $10 \mu \mathrm{mol} / \mathrm{l} \mathrm{RES}$ groups compared with the $50 \mu \mathrm{mol} / 1 \mathrm{RES}$ group. Serum levels of IL-1, IL-10 and TNF- $\alpha$ were elevated, whereas IL-12 was reduced in asthmatic children compared with healthy children. The present results demonstrated that a large dose of RES alleviated asthma-induced airway inflammation and airway remodeling by inhibiting the release of inflammatory cytokines via the HMGB1/TLR4/NF- $\kappa$ B pathway.

\section{Introduction}

Asthma is a common chronic respiratory disease in children. Its main pathological features are airway inflammation and airway remodeling. Eosinophils, neutrophils and other inflammatory cells participate in asthma-induced airway remodeling (1-3). As a chronic inflammatory disease, asthma may progress to irreversible airway remodeling without the appropriate treatment (4). Research has identified that asthma pathogenesis involves multiple mechanisms, including genetic mechanisms, the immune response, chronic airway inflammation, airway hyper responsiveness, airway neuromodulation disorders and neural signaling pathway (5-7). The immune response is the leading pathogenic factor.

High mobility group box 1 (HMGB1) is a highly conserved nuclear protein that is released by mononuclear cells, macrophages and other immune cells following stimulation by lipopolysaccharide, tumor necrosis factor- $\alpha$ (TNF- $\alpha)$ or interleukin (IL)-1. HMGB1 is also passively released from damaged and necrotic tissue cells to further promote the secretion of a number of inflammatory factors. As a vital endogenous pro-inflammatory factor and inflammatory mediator, HMGB1 participates in the pathological processes of sepsis, pneumonia, arthritis and other diseases $(8,9)$. Extracellular HMGB1 promotes cytokine release via the mitogen-activated protein kinase (MAPK), ERK1/2 and NF- $\mathrm{BB}$ pathways (10). HMGB1 also activates Toll-like receptor (TLR) 2 and TLR4, which in turn leads to a downstream inflammatory response via targeting myeloid differentiation primary response gene 88 (MyD88) and NF- $\mathrm{B}$ (11). It has been demonstrated that TLR4 is an essential receptor in HMGB1-induced inflammation (12). HMGB1 exerts its pro-inflammatory role via binding to TLR4 leading to release of inflammatory cytokines 
such as IL- $\beta$, IL-10, IL-12 and TNF $\alpha(13,14)$. The present study hypothesized that the HMGB1/TLR4/NF- $\kappa \mathrm{B}$ pathway may be of great significance in the pathogenesis of asthma.

In recent years, resveratrol (RES) has attracted research focus due to its low toxicity and wide range of action. Beneficial effects of RES have been demonstrated in pulmonary fibrosis, chronic obstructive pulmonary disease, pulmonary hypertension and other lung diseases (15-17). RES can effectively inhibit eosinophil activation and degranulation (18), and alleviate airway inflammation and airway hyper-responsiveness in an acute asthma model (19). In addition, RES regulates the differentiation of type $1 \mathrm{~T}$ helper (Th1)/Th2 cells through Tbet/GATA binding protein 3 pathway, suggesting that RES may have a role in protecting against bronchial asthma (20). However, the specific mechanisms of RES in regards to asthma remains not fully understood. The present study first constructed an asthma rat model. Following intervention with different doses of RES, the alterations in rat airway remodeling and the HMGB1/TLR4/NF- $\mathrm{B}$ pathway were observed. These findings provided a theoretical basis for improving clinical asthma outcomes in children.

\section{Materials and methods}

Animal procedures. A total of 40 male Sprague Dawley rats (age, 4 weeks; weight, $80 \pm 15 \mathrm{~g}$ ) were purchased from Beijing Vital River Laboratory Animal Technology Co., Ltd. and housed at $24 \pm 3^{\circ} \mathrm{C}$ and humidity of $40-60 \%$ on a 12 -h light/dark cycle (lights on at 06:00 am). The rats were provided food and water ad libitum. Rats were acclimated for 1 week and subsequently randomly assigned into the sham, asthma, $10 \mu \mathrm{mol} / 1$ RES or $50 \mu \mathrm{mol} / 1$ RES groups $(\mathrm{n}=10)$.

Asthma rat model construction. A total of $0.2 \mathrm{ml}$ of mixed antigen [2 $\mathrm{mg}$ ovalbumin (OVA) + $40 \mathrm{mg}$ aluminum hydroxide] solution (Sigma-Aldrich; Merck KGaA) was intraperitoneally injected into rats of the asthma group, $10 \mu \mathrm{mol} / 1$ RES (Sigma-Aldrich; Merck KGaA) group and $50 \mu \mathrm{mol} / 1$ RES group on day 1, 8 and 15 , respectively. Rats in the sham group received intraperitoneal injection of $0.2 \mathrm{ml}$ of saline. On day 22, rats in the asthma group, $10 \mu \mathrm{mol} / 1$ RES group and $50 \mu \mathrm{mol} / 1 \mathrm{RES}$ group received atomization inhalation of $1 \%$ OVA to induce the asthma model. For the RES group rats, $30 \mathrm{~min}$ before inhalation of OVA, $0.2 \mathrm{ml}$ of either $10 \mu \mathrm{mol} / 1$ or $50 \mu \mathrm{mol} / 1 \mathrm{RES}$ was injected intraperitoneally into rats. Rats in the sham group and asthma group were injected with $0.2 \mathrm{ml}$ of saline. The experiment lasted until day 35 .

Bronchoalveolar lavage fluid (BALF) sample collection. Rats were anesthetized with $1 \%$ sodium pentobarbital $(40 \mathrm{mg} / \mathrm{kg})$ intraperitoneally prior to collection of BALF. In brief, $1 \mathrm{ml}$ of saline was injected into rats then repeat suction was performed three times. BALF was recycled and centrifuged at $400 \times \mathrm{g}$ for $15 \mathrm{~min}$ at $4^{\circ} \mathrm{C}$. A sample was considered as suitable for experimentation when the recycled amount was $>0.8 \mathrm{ml}$. Cell counting was performed within $1 \mathrm{~h}$. Cell sedimentation was resuspended with PBS solution, then $10 \mu \mathrm{l}$ was used for measurement of total cell number. Then $0.1 \mathrm{ml}$ was used for cell pellets smear. The cell pellets smear was fixed and stained with Wright's staining. Cells were differential counted in three visual field and the values were averaged as previously described in the literature (19).

Hematoxylin and eosin $(H \& E)$ staining. The right lung tissue of rats was fixed with $10 \%$ paraformaldehyde (Sigma-Aldrich; Merck KGaA) at room temperature for $48 \mathrm{~h}$. Then the tissue was dehydrated in an ascending series of ethanol, embedded in paraffin and sectioned $(5 \mu \mathrm{m})$. Following deparaffinization in xylene and rehydration in a descending series of alcohol, lung tissues were stained with H\&E. Inflammatory cell infiltration and airway epithelial injury were observed under a light microscope.

Masson staining. The aforementioned paraffin embedded slices (5 $\mu \mathrm{m})$ were stained with Weigert solution (Sigma-Aldrich; Merck KGaA) for 5-10 min. After being fully washed, sections were treated with Ponceau fuchsin acid solution for 5-10 min, immersed in $2 \%$ acetic acid aqueous solution for $1 \mathrm{~min}$, then differentiated in $1 \%$ phosphomolybdic acid aqueous solution for 3-5 min. Without washing with water, the sections were treated with aniline blue for $5 \mathrm{~min}$ then immersed in $0.2 \%$ acetic acid aqueous solution for $1 \mathrm{~min}$. Slices were permeabilized with xylene and mounted with neutral resin.

Measurement of the thicknesses of airway wall and smooth muscle. The intact small bronchioles were identified using a light microscope. Three transverse sections were randomly selected in each rat. Basement membrane perimeter (Pbm), total bronchial wall area $\left(\mathrm{Wat}_{1}\right)$, bronchial luminal area $\left(\mathrm{Wat}_{2}\right)$, external smooth muscle area $\left(\mathrm{Wam}_{1}\right)$ and internal smooth muscle area $\left(\mathrm{Wam}_{2}\right)$ of each rat were accessed using Image Pro Plus v.6.0 software (Media Cybernetics, Inc.). The thickness of airway wall (Wan) and smooth muscle (Wat) were then calculated using the following formulas:

(1) $\mathrm{Wan}=\left(\mathrm{Wat}_{1}-\mathrm{Wat}_{2}\right) / \mathrm{Pbm}$

(2) $\mathrm{Wat}=\left(\mathrm{Wam}_{1}-\mathrm{Wam}_{2}\right) / \mathrm{Pbm}$

Determination of inflammatory factors in lung homogenate. Harvested rat lung tissue $(0.5 \mathrm{~g})$ was ground and centrifuged at $4,500 \mathrm{x}$ g for $10 \mathrm{~min}$ at $4^{\circ} \mathrm{C}$ for preparation of lung homogenate. Levels of IL-1, IL-10, IL-12 and TNF- $\alpha$ in rat lung homogenate were detected using the respective ELISA kits (Rat IL-1 ELISA kit, cat. no. RAB0272; Rat IL-10 ELISA kit, cat. no. RAB0246; Rat TNF- $\alpha$ ELISA kit cat. no. RAB0480; all from Sigma-Aldrich; Merck KGaA; and Rat IL-12 ELISA kit, cat. no. KRC0121; Invitrogen; Thermo Fisher Scientific, Inc.) according to the manufacturer's instructions.

Reverse transcription-quantitative PCR (RT-qPCR). The lung tissue $(0.5 \mathrm{~g})$ was cut and homogenized; TRIzol (Invitrogen; Thermo Fisher Scientific, Inc.) was used to extract total RNA. Total RNA underwent reverse transcription according to the instructions of PrimeScript RT reagent Kit (Takara Bio, Inc.). qPCR was performed using SYBR ${ }^{\circledR}$-Green Master Mix (Takara Bio, Inc.) according to the manufacturer's protocol; amplification was performed under the recommended parameters: Initial denaturation at $95^{\circ} \mathrm{C}$ for $5 \mathrm{~min}$, followed by 40 cycles of $95^{\circ} \mathrm{C}$ for $5 \mathrm{sec}, 60^{\circ} \mathrm{C}$ for $15 \mathrm{sec}$ and $72^{\circ} \mathrm{C}$ for $15 \mathrm{sec}$, and a final extension at $94^{\circ} \mathrm{C}$ for $15 \mathrm{sec}$. The expression level of the target gene was calculated using the $2^{-\Delta \Delta \mathrm{Cq}}$ method (21). Primers are listed in Table I. 
Table I. Primer sequences.

\begin{tabular}{lcl}
$\begin{array}{l}\text { Gene } \\
\text { name }\end{array}$ & $\begin{array}{c}\text { PCR } \\
\text { size }(\mathrm{bp})\end{array}$ & \multicolumn{1}{c}{ Primer sequence $\left(5^{\prime} \rightarrow 3^{\prime}\right)$} \\
\hline HMGB1 & 356 & $\begin{array}{l}\text { F: CGGATGCTTCTGTCAACT } \\
\text { R: TCAGCTTGGCAGCTTTCT }\end{array}$ \\
TLR4 & \multirow{2}{*}{310} & $\begin{array}{l}\text { F: GGTGAGAAATGAGCTGGTA } \\
\text { R: TCTGCTAAGAAGGCGATA }\end{array}$ \\
MyD88 & \multirow{2}{*}{113} & $\begin{array}{l}\text { F: CGTCGCATGGTGGTGTTGTT } \\
\text { R: GGGATCAGTCGCTTCTGTTGA }\end{array}$ \\
NF-kB & \multirow{2}{*}{425} & $\begin{array}{l}\text { F: GCGCATCCAGACCAACAATAAC } \\
\text { R: GCCGAAGCTGCATGGACACT }\end{array}$ \\
GAPDH & 526 & $\begin{array}{l}\text { F CCACTTGAAGGGTGAGC } \\
\text { R: TGAAGTCGCAGGAGACAA }\end{array}$
\end{tabular}

HMGB1, high mobility group box 1; MyD88, myeloid differentiation primary response gene 88 ; TLR4, Toll-like receptor; R, reverse; F, forward.

Determination of inflammatory factors in serum of children. A total of 34 pediatric patients with asthma (age, 4-14 years; 19 male, 15 female), admitted to The Affiliated Changzhou No. 2 People's Hospital of Nanjing Medical University (Changzhou, China) from January 2018 to May 2018 were selected as the asthma group. The diagnosis of childhood asthma conforms to the diagnostic criteria in the Guidelines for the Diagnosis and Prevention of Childhood Bronchial Asthma, formulated by the Respiratory Group of the Chinese Medical Association in 2008. Exclusion criteria: i) Patients with other tracheal, bronchial or pulmonary diseases; ii) patients with severe multiple organ, nervous or psychiatric diseases. Subjects were all in the acute asthmatic stage regardless of the severity of the attack. For the control group, 24 healthy children (age, 4-12 years; 13 male, 11 female) were selected during the same period. From each subject, $5 \mathrm{ml}$ of venous blood sample was collected for detecting serum levels of IL-1, IL-10, IL-12 and TNF- $\alpha$ by ELISA. Written informed consent was obtained from the legal guardians for all patients and healthy controls.

Statistical analysis. Data were analyzed by SPSS v.17.0 statistical software (SPSS Inc.). Quantitative data were presented as mean \pm standard deviation. Student's t-test was used for comparing differences between two groups. One-way analysis of variance was performed for assessing differences amongst multiple groups, followed by Fisher's least significant difference analysis or Dunnett's test. $\mathrm{P}<0.05$ was considered to indicate statistical significance.

\section{Results}

High dose RES treatment attenuates pathological lesions in a rat asthma model. Pronounced pathological lesions were observed in the lung tissues of the asthma group, manifesting as edema and abscission of airway epithelium, airway constriction, multiple inflammatory cell infiltration and tracheal smooth muscle thickening (Fig. 1A). In addition, marked capillary congestion, alveolar fusion enlargement and alveolar septum widening were observed in asthma rats (Fig. 1A). Pathological changes were similar in the $10 \mu \mathrm{mol} / 1 \mathrm{RES}$ group. By contrast, pathological changes in lung tissues were less pronounced in the $50 \mu \mathrm{mol} / \mathrm{l}$ RES group compared with the asthma group (Fig. 1A).

High dose RES treatment decreases airway collagen deposition area. Masson staining is commonly used to stain collagen fibers, mucus and cartilage blue. Muscle fibers, cellulose and red blood cells are stained red, whilst cell nuclei are stained blue-black. Airway collagen deposition was more marked in the asthma group compared with the sham group (Fig. 1B). No significant difference in airway collagen deposition area was observed between the asthma group and $10 \mu \mathrm{mol} / \mathrm{l} \mathrm{RES}$ group (Fig. 1B). By contrast, the airway collagen deposition area was markedly reduced in the $50 \mu \mathrm{mol} / 1$ RES group compared with the asthma group (Fig. 1B).

High dose RES treatment decreases inflammatory cell levels in the BALF of asthma model rats. Total amounts of inflammatory cells, eosinophils and lymphocytes were elevated in the asthma group and the $10 \mu \mathrm{mol} / 1 \mathrm{RES}$ group compared with the sham group $(\mathrm{P}<0.05$; Fig. $2 \mathrm{~A}-\mathrm{C})$. By contrast, the amounts of inflammatory cells, eosinophils and lymphocytes were significantly decreased in the $50 \mu \mathrm{mol} / \mathrm{l}$ RES group $(\mathrm{P}<0.05$; Fig. 2A-C).

High dose RES treatment decreases airway wall and smooth muscle thickness in asthma model rats. Airway wall and smooth muscle thickness were increased in the asthma group and $10 \mu \mathrm{mol} / 1 \mathrm{RES}$ group compared to the sham group ( $\mathrm{P}<0.05$; Fig. 2D and E). Treatment with $50 \mu \mathrm{mol} / 1$ RES decreased airway wall and smooth muscle thickness $(\mathrm{P}<0.05$; Fig. 2D and $\mathrm{E})$.

High dose RES treatment decreases inflammatory factor levels in lung tissues of asthma model rats. ELISA results illustrated that IL-1, IL-10 and TNF- $\alpha$ levels in lung tissues of the asthma and $10 \mu \mathrm{mol} / \mathrm{l} \mathrm{RES}$ groups were elevated, whereas IL-12 level was reduced ( $\mathrm{P}<0.05$; Fig. 3 ). In the $50 \mu \mathrm{mol} / 1 \mathrm{RES}$ group, IL-1, IL-10 and TNF- $\alpha$ levels were downregulated but IL-12 was upregulated in rat lung tissues following establishment of the asthma model $(\mathrm{P}<0.05$; Fig. 3).

High dose RES treatment reduces HMGB1, TLR4, MyD88 and $N F-\kappa B$ expression in asthma model rats. HMGB1, TLR4, MyD88 and NF- $\kappa \mathrm{B}$ mRNA expression levels were remarkably elevated in rats of the asthma and $10 \mu \mathrm{mol} / 1 \mathrm{RES}$ groups compared with the sham group $(\mathrm{P}<0.05$; Fig. 4). By contrast, $50 \mu \mathrm{mol} / 1$ RES treatment significantly decreased HMGB1, TLR4, MyD88 and NF- $\kappa \mathrm{B}$ mRNA expression in rat lung tissue following establishment of the asthma model ( $\mathrm{P}<0.05$; Fig. 4).

Inflammatory factor levels increase in serum samples of asthmatic children. Serum levels of IL-1, IL-10, IL-12 and TNF- $\alpha$ in asthma children and healthy children were analyzed. Asthmatic children had increased IL-1, IL-10 and TNF- $\alpha$ serum levels, as well as decreased IL-12 levels compared with healthy children $(\mathrm{P}<0.05$; Fig. 5). 
A

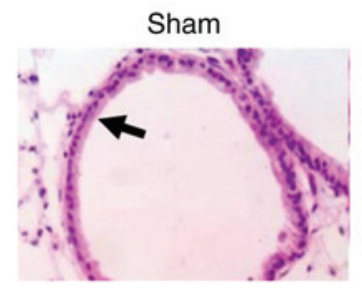

$10 \mu \mathrm{mol} / \mathrm{RES}$

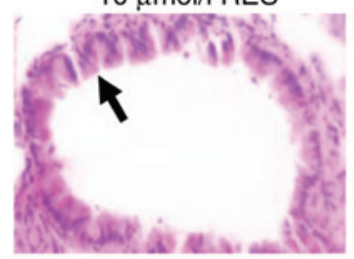

Asthma

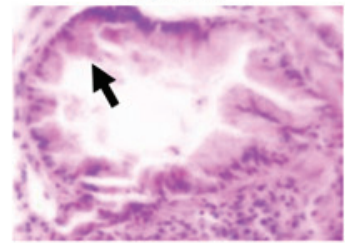

$50 \mu \mathrm{mol} / \mathrm{l}$ RES

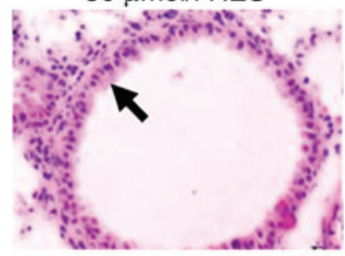

B

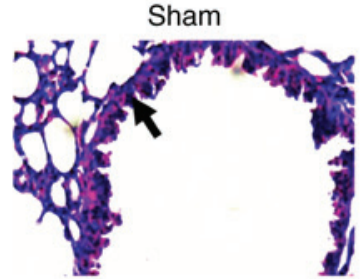

$10 \mu \mathrm{mol} / \mathrm{RES}$

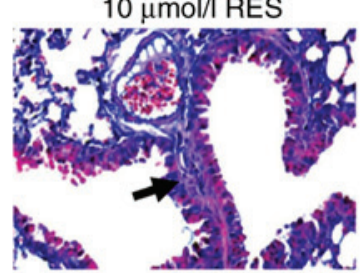

Asthma

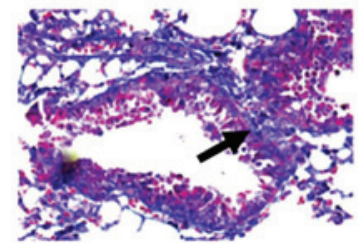

$50 \mu \mathrm{mol} / \mathrm{l}$ RES

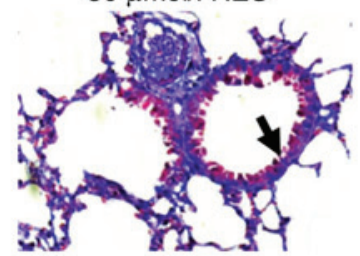

Figure 1. Hematoxylin and eosin, and 2 of rat lung tissues demonstrating pathological lesions and collagen deposition following establishment of an asthma rat model. (A) Pathological lesions in rat lung tissue of sham, asthma, $10 \mu \mathrm{mol} / 1 \mathrm{RES}$ and $50 \mu \mathrm{mol} / 1 \mathrm{RES}$ groups. (B) Alterations of airway collage deposition (blue staining) in rat lung tissues of sham, asthma, $10 \mu \mathrm{mol} / 1 \mathrm{RES}$ and $50 \mu \mathrm{mol} / 1 \mathrm{RES}$ groups (magnification, x200). RES, resveratrol.

A

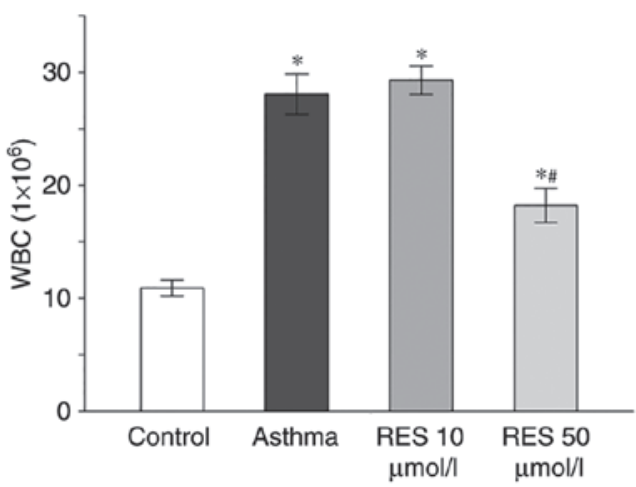

C

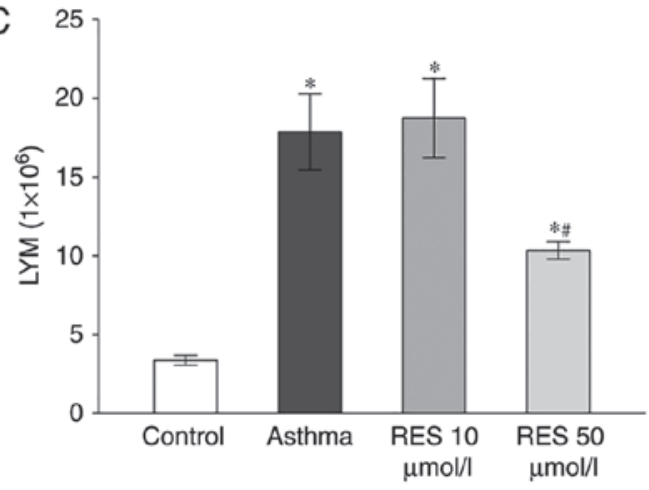

B

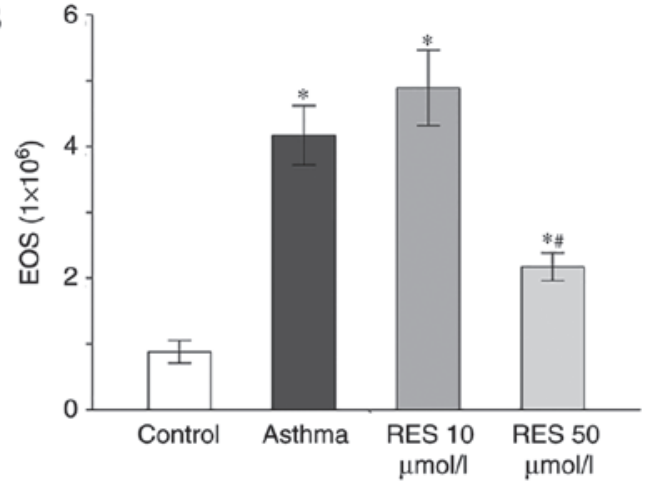

D

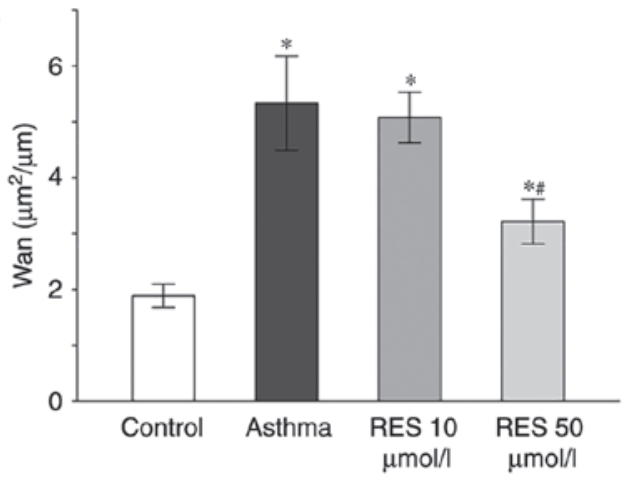

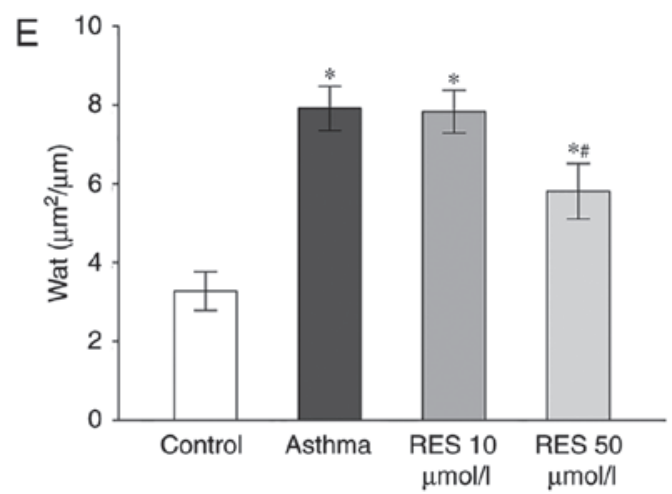

Figure 2. Inflammatory cell amount in BALF, and airway wall and smooth muscle thickness for sham, asthma, $10 \mu \mathrm{mol} / 1 \mathrm{RES}$ and $50 \mu \mathrm{mol} / 1 \mathrm{RES}$ groups. (A) Number of inflammatory cells in rat BALF for different groups. (B) Number of eosinophils for different groups. (C) Number of lymphocytes for different groups. (D) Thickness of airway wall for different groups. (E) Thickness of airway smooth muscle for different groups. * $<<0.05$ vs. sham group; ${ }^{\#} \mathrm{P}<0.05$ vs. asthma group. BALF, bronchoalveolar lavage fluid; RES, resveratrol; EOS, eosinophils; LYM, lymphocytes; Wan, the thickness of airway wall; Wat, the thickness of smooth muscle. 
A
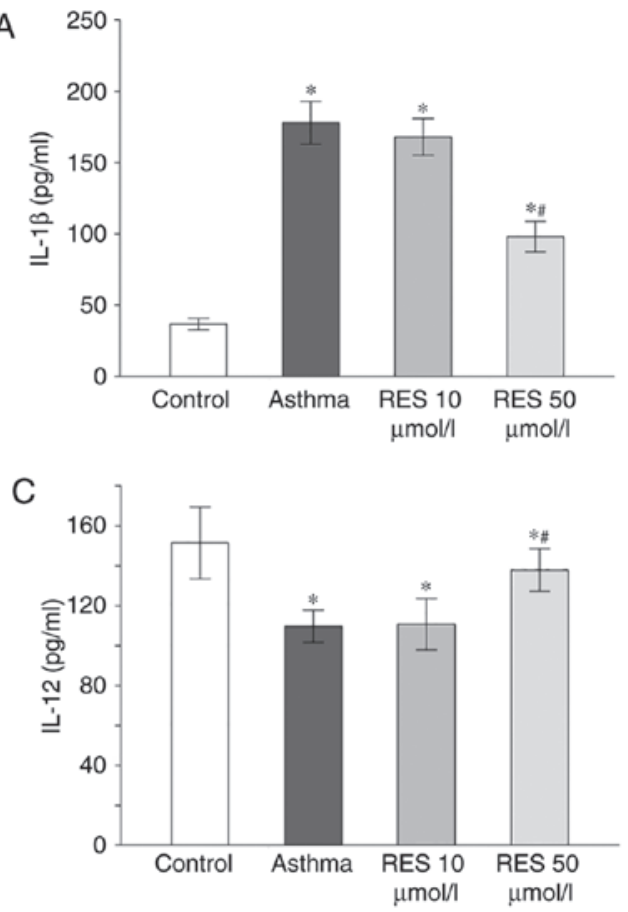

B
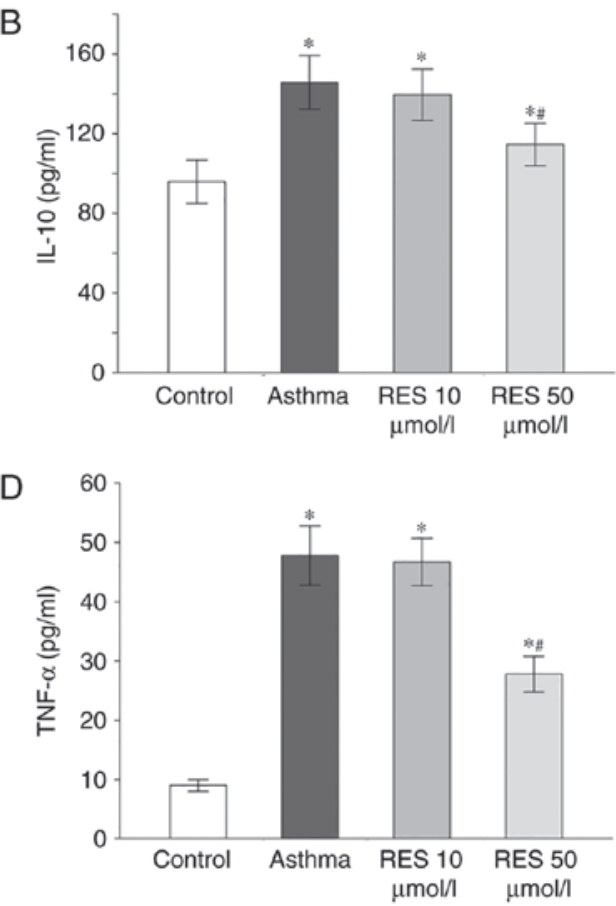

Figure 3. IL-1, IL-10, IL-12 and TNF- $\alpha$ levels in rat lung tissues for sham, asthma, $10 \mu \mathrm{mol} / 1$ RES and $50 \mu \mathrm{mol} / 1$ RES groups. (A) IL-1 $\beta$, (B) IL-10, (C) IL-12, and (D) TNF- $\alpha$ levels in rat lung tissues from the different experimental groups. ${ }^{*} \mathrm{P}<0.05$ vs. control; ${ }^{*} \mathrm{P}<0.05$ vs. asthma group. IL, interleukin; TNF- $\alpha$, tumor necrosis factor- $\alpha$; RES, resveratrol.

A
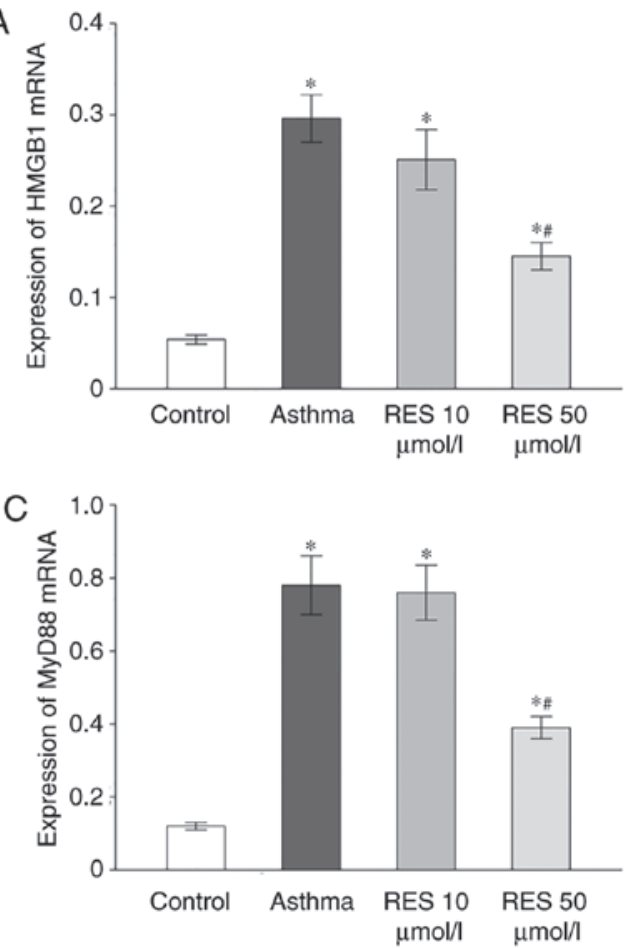

B
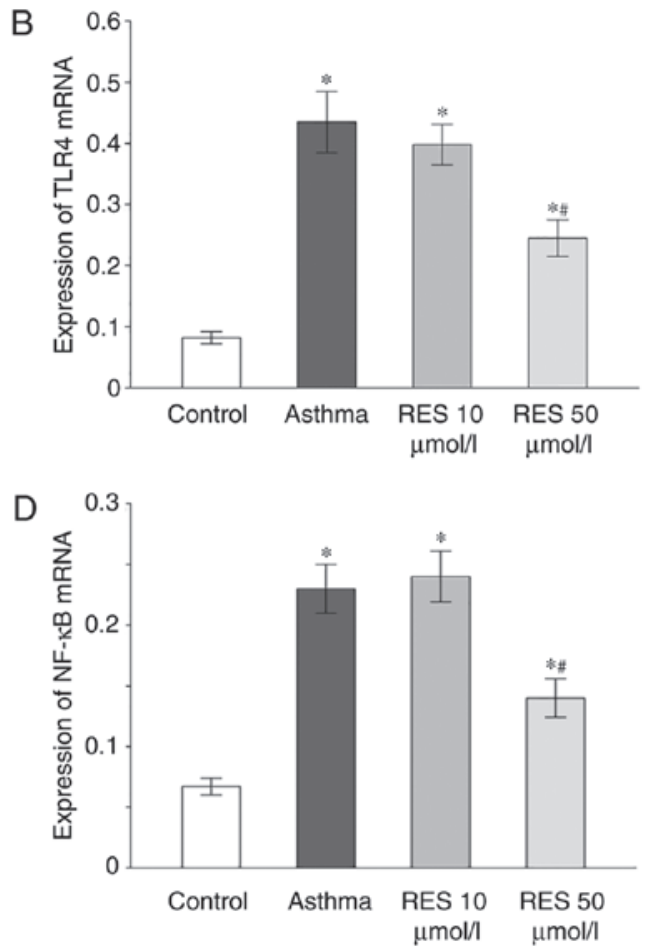

Figure 4. HMGB1, TLR4, MyD88 and NF-kB mRNA expression in rat lung tissues for sham, asthma, $10 \mu \mathrm{mol} / 1$ RES and $50 \mu \mathrm{mol} / 1$ RES groups. (A) HMGB1,

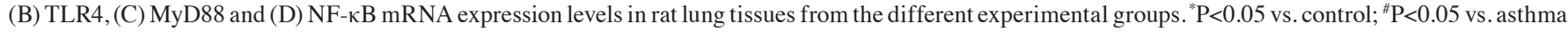
group. HMGB1, high mobility group box 1; TLR4, Toll-like receptor; MyD88, myeloid differentiation primary response gene 88; RES, resveratrol.

\section{Discussion}

Bronchial asthma in children is a common disease that can severely influence daily life (1). Asthma can progress to adulthood if proper and timely treatment is not received.
Pathologically, asthma is an airway chronic inflammatory disease involving a variety of cells and cellular components. Airway inflammation and remodeling are important pathological features of chronic asthma. IL-1 $\beta$ has an important role in the development of allergic asthma by inducing the formation 

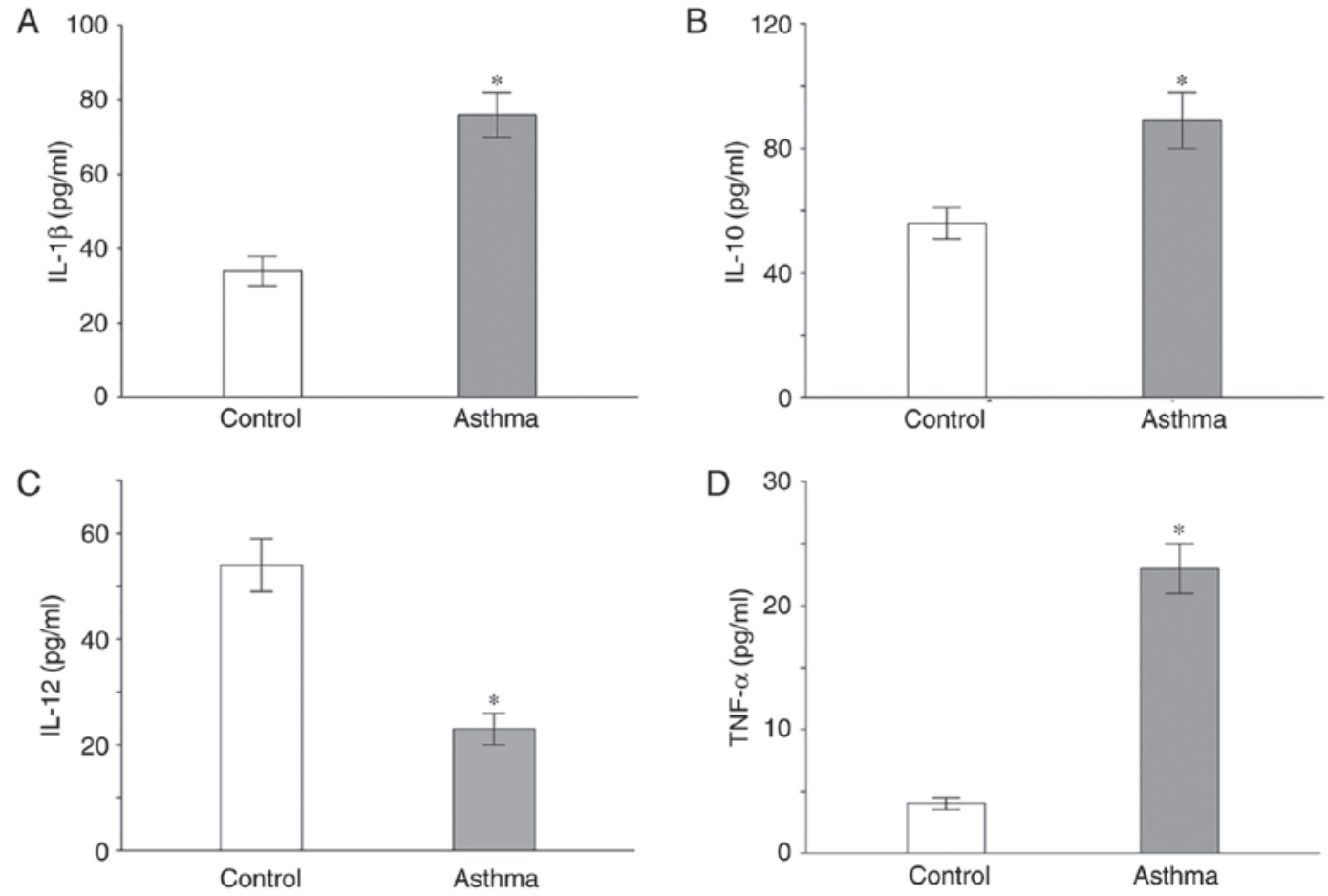

Figure 5. Inflammatory factor levels in serum samples of asthmatic and healthy children. (A) Serum levels of IL-1 $\beta$, (B) IL-10, (C) IL-12 and (D) TNF- $\alpha$. ${ }^{*} \mathrm{P}<0.05$ vs. control. IL, interleukin; TNF- $\alpha$, tumor necrosis factor- $\alpha$.

of Th17 cells (22). IL-10 can regulate immune function and improve airway inflammatory response (23). IL-12 is a Th1 cytokine, which increases airway hyper responsiveness due to exogenous injury and decreases eosinophil aggregation around the airway (24). The present study determined that serum levels of IL-1, IL-10 and TNF- $\alpha$ in lung tissues of asthma model rats and serum samples of asthmatic children were significantly elevated. By contrast, IL-12 level was decreased. These results indicated that the inflammatory response is involved in the occurrence and progression of asthma.

HMGB1 is widely present in the cell nucleus and cytoplasm. Nuclear membrane permeability is increased by inflammation, which in turn promotes the translocation of HMGB1 to the cell cytoplasm where it exerts pro-inflammatory effects $(14,25,26)$. HMGB1 stimulates mononuclear cell and macrophage-secreted inflammatory mediators, such as IL-1 $\beta$, IL-10, IL-12 and TNF- $\alpha$ (27). In addition, HMGB1 promotes major histocompatibility complex II, CD80, CD83, CD86 and other costimulatory molecules in dendritic cells (DCs), inducing DC maturation to produce pro-inflammatory cytokines (28). Eosinophils are recruited by HMGB1 to the inflammatory sites further aggravating the inflammatory response $(29,30)$. Recent studies have identified that HMGB2 deteriorates airway inflammation by upregulating TNF- $\alpha$, VEGF, MMP-9 and TSLP expression. HMGB1 knockdown remarkably decreases relative indicators of airway inflammation, mucus secretion, collagen deposition, and airway smooth muscle thickness (31). TLR4 was the first TLR identified in mammals; it comprises an extracellular domain, a transmembrane domain and an intracellular domain $(32,33)$. Relative studies have demonstrated that TLR4 is involved in the regulation of airway inflammation through regulating DC maturation and activation, antigen presentation and $\mathrm{T}$ cell immune responses. TLR4 is overexpressed in airway smooth muscle cells by elastase stimulation, leading to thickening of the airway wall via activation of NF-kB (34) therefore it is evident that TLR4 participates in airway remodeling. NF- $\kappa B$ is a nuclear transcription factor with various biological activities. NF- $\kappa \mathrm{B}$ pathway regulates genes involved in asthma-related airway inflammation (35). Inhibition of NF- $\kappa \mathrm{B}$ activity alleviates the airway inflammatory response, thereafter improving airway remodeling. TLR4 activates NF- $\mathrm{KB}$ through MyD88-dependent and MyD88-independent ways, eventually stimulating the production of pro-inflammatory factors. HMBG1 induces the immune and inflammatory response after binding to its receptor TLR4 $(36,37)$. It is hypothesized that the HMGB1/TLR4/NF- $\kappa B$ pathway may serve an important role in the development and progression of asthma.

RES is a plant polyphenolic substance present in grape skins, berries and nuts (38). Numerous studies have demonstrated that RES exerts anti-apoptosis, anti-inflammatory and anti-oxidative effects in vitro (39-43). RES also alleviates airway inflammation and airway hyper responsiveness in vivo, partially through inhibiting eosinophil activation and degranulation $(18,19)$. The most pronounced effect of RES is inflammation alleviation, mainly via NF- $\kappa \mathrm{B}$ pathway regulation $(44,45)$. RES is capable of inhibiting TLR4 expression in cardiomyocytes with hypoxia-reoxygenation injury (46). However, the pathogenesis of asthma and the mechanism of RES on asthma are complex. In the present study, airway lesions were obvious in asthma model rats, manifesting as abundant inflammatory cell infiltration. Pathological lesions in rat airways were remarkably alleviated by treatment with $50 \mu \mathrm{mol} / 1 \mathrm{RES}$. However, $10 \mu \mathrm{mol} / \mathrm{l}$ RES treatment did not present therapeutic effect on asthma-induced inflammation. HMGB1, TLR4, MyD88 and NF- $\kappa B$ mRNA levels in 
$50 \mu \mathrm{mol} / 1$ RES group were significantly lower compared with the asthma group. Treatment with $10 \mu \mathrm{mol} / 1 \mathrm{RES}$ did not affect HMGB1, TLR4, MyD88 and NF- $\kappa$ B mRNA levels following establishment of an asthma model. The results confirmed that HMGB1 and TLR4 were involved in asthma-induced airway inflammation. However, the present study used only RT-qPCR to detect HMGB1, TLR4, MyD88 and NF- $\mathrm{BB}$ levels; additional experimental methods should be investigated in future work. In addition, detection of the remodeling-associated proteins and verification of which cell type is targeted by RES require to be further elucidated. Finally, the relationship of the HMGB1/TLR4/MyD88/NF- $\kappa$ B axis and RES will be further studied in future work.

In conclusion, the present study demonstrated that large dose RES alleviated asthma-induced airway inflammation and airway remodeling by inhibiting the release of inflammatory cytokines via the HMGB1/TLR4/NF- $\kappa$ B pathway. The present results provided evidence for RES as a potential novel treatment for asthma.

\section{Acknowledgements}

Not applicable.

\section{Funding}

No funding was received.

\section{Availability of data and materials}

The datasets generated and/or analyzed during the current study are available from the corresponding author on reasonable request.

\section{Authors' contributions}

HJ and WZ designed the study and performed the experiments. HJ, JD and KX established the animal models. HJ and KX collected the data. HJ and KX analyzed the data. HJ and WZ prepared the manuscript. All authors read and approved the final manuscript.

\section{Ethics approval and consent to participate}

Experimental protocols involving the use of animals were approved by the Animal Ethics Committee of Nanjing Medical University Animal Center. Protocols involving the use of human samples were approved by the Ethics Committee of the Affiliated Changzhou No. 2 People's Hospital of Nanjing Medical University (Changzhou, China). Written informed consent was obtained from the legal guardians of all patients and healthy controls.

\section{Patient consent for publication}

Not applicable.

\section{Competing interests}

Not applicable.

\section{References}

1. Guilbert TW, Mauger DT and Lemanske RF Jr: Childhood asthma-predictive phenotype. J Allergy Clin Immunol Pract 2: 664-670, 2014.

2. Pinfield J, Gaskin K, Bentley J and Rouse J: Recognition and management of asthma in children and young people. Nurs Stand 30: 50-58, 2015

3. Us'Ka VR: Role of psychological factors in the etiology of asthma in children. Lik Sprava: 148-150, 2015 (In Ukrainian).

4. Croisant S: Epidemiology of asthma: Prevalence and burden of disease. Adv Exp Med Biol 795: 17-29, 2014.

5. Raedler D and Schaub B: Immune mechanisms and development of childhood asthma. Lancet Respir Med 2: 647-656, 2014.

6. Rosenberg SL, Miller GE, Brehm JM and Celedon JC: Stress and asthma: Novel insights on genetic, epigenetic and immunologic mechanisms. J Allergy Clin Immunol 134: 1009-1015, 2014.

7. Khan DA: Allergic rhinitis and asthma: Epidemiology and common pathophysiology. Allergy Asthma Proc 35: 357-361, 2014.

8. Yang Q, Liu X, Yao Z, Mao S, Wei Q and Chang Y: Penehyclidine hydrochloride inhibits the release of high-mobility group box 1 in lipopolysaccharide-activated RAW264.7 cells and cecal ligation and puncture-induced septic mice. J Surg Res 186: 310-317, 2014.

9. Musumeci D, Roviello GN and Montesarchio D: An overview on HMGB1 inhibitors as potential therapeutic agents in HMGB1-related pathologies. Pharmacol Ther 141: 347-357, 2014.

10. Dumitriu IE, Baruah P, Valentinis B, Voll RE, Herrmann M, Nawroth PP, Arnold B, Bianchi ME, Manfredi AA and Rovere-Querini P: Release of high mobility group box 1 by dendritic cells controls $T$ cell activation via the receptor for advanced glycation end products. J Immunol 174: 7506-7515, 2005.

11. Park JS, Svetkauskaite D, He Q, Kim JY, Strassheim D, Ishizaka A and Abraham E: Involvement of Toll-like receptors 2 and 4 in cellular activation by high mobility group box 1 protein. J Biol Chem 279: 7370-7377, 2004

12. Yang H, Hreggvidsdottir HS, Palmblad K, Wang H, Ochani M, Li J, Lu B, Chavan S, Rosas-Ballina M, Al-Abed Y, et al: A critical cysteine is required for HMGB1 binding to Toll-like receptor 4 and activation of macrophage cytokine release. Proc Natl Acad Sci USA 107: 11942-11947, 2010.

13. Andersson U, Wang H, Palmblad K, Aveberger AC, Bloom O, Erlandsson-Harris H, Janson A, Kokkola R, Zhang M, Yang H and Tracey KJ: High mobility group 1 protein (HMG-1) stimulates proinflammatory cytokine synthesis in human monocytes. J Exp Med 192: 565-570, 2000.

14. Park JS, Arcaroli J, Yum HK, Yang H, Wang H, Yang KY, Choe KH, Strassheim D, Pitts TM, Tracey KJ and Abraham E: Activation of gene expression in human neutrophils by high mobility group box 1 protein. Am J Physiol Cell Physiol 284: C870-C879, 2003.

15. Wang J, He F, Chen L, Li Q, Jin S, Zheng H, Lin J, Zhang H, Ma S, Mei J and Yu J: Resveratrol inhibits pulmonary fibrosis by regulating miR-21 through MAPK/AP-1 pathways. Biomed Pharmacother 105: 37-44, 2018.

16. Wang XL, Li T, Li JH, Miao SY and Xiao XZ: The effects of resveratrol on inflammation and oxidative stress in a rat model of chronic obstructive pulmonary disease. Molecules 22: E1529, 2017.

17. Yang DL, Zhang HG, Xu YL, Gao YH, Yang XJ, Hao XQ and Li XH: Resveratrol inhibits right ventricular hypertrophy induced by monocrotaline in rats. Clin Exp Pharmacol Physiol 37: 150-155, 2010.

18. Oh YC, Kang OH, Choi JG, Chae HS, Lee YS, Brice OO, Jung HJ, Hong SH, Lee YM and Kwon DY: Anti-inflammatory effect of resveratrol by inhibition of IL-8 production in LPS-induced THP-1 cells. Am J Chin Med 37: 1203-1214, 2009.

19. Tan Y and Lim LH: Trans-Resveratrol, an extract of red wine, inhibits human eosinophil activation and degranulation. $\mathrm{Br}$ J Pharmacol 155: 995-1004, 2008.

20. Colitti M and Stefanon B: Different anti-adipogenic effects of bio-compounds on primary visceral pre-adipocytes and adipocytes. EXCLI J 15: 362-377, 2016.

21. Livak KJ and Schmittgen TD: Analysis of relative gene expression data using real-time quantitative PCR and the 2(-Delta Delta $\mathrm{C}(\mathrm{T})$ ) method. Methods 25: 402-408, 2001. 
22. Ebenezer AJ, Prasad K, Rajan S and Thangam EB: Silencing of H4R inhibits the production of IL- $1 \beta$ through SAPK/JNK signaling in human mast cells. J Recept Signal Transduct Res 38 : 204-212, 2018

23. Zhang Y, Feng Y, Li L, Ye X, Wang J, Wang Q,Li P, Li N,Zheng X Gao X, et al: Immunization with an adenovirus-vectored TB vaccine containing Ag85A-Mtb32 effectively alleviates allergic asthma. J Mol Med (Berl) 96: 249-263, 2018.

24. Lin CL, Hsiao G, Wang CC and Lee YL: Imperatorin exerts antiallergic effects in Th2-mediated allergic asthma via induction of IL-10-producing regulatory T cells by modulating the function of dendritic cells. Pharmacol Res 110: 111-121, 2016.

25. Abraham E, Arcaroli J, Carmody A, Wang H and Tracey KJ: HMG-1 as a mediator of acute lung inflammation. J Immunol 165 : 2950-2954, 2000.

26. Kim JY, Park JS, Strassheim D, Douglas I, Diaz del Valle F, Asehnoune K, Mitra S, Kwak SH, Yamada S, Maruyama I, et al: HMGB1 contributes to the development of acute lung injury after hemorrhage. Am J Physiol Lung Cell Mol Physiol 288: L958-L965, 2005.

27. Bauer EM, Shapiro R, Zheng H, Ahmad F, Ishizawar D, Comhair SA, Erzurum SC, Billiar TR and Bauer PM: High mobility group box 1 contributes to the pathogenesis of experimental pulmonary hypertension via activation of Toll-like receptor 4. Mol Med 18: 1509-1518, 2013.

28. Dumitriu IE, Bianchi ME, Bacci M, Manfredi AA and Rovere-Querini P: The secretion of HMGB1 is required for the migration of maturing dendritic cells. J Leukoc Biol 81: 84-91, 2007.

29. Messmer D, Yang H, Telusma G, Knoll F, Li J, Messmer B, Tracey KJ and Chiorazzi N: High mobility group box protein 1 An endogenous signal for dendritic cell maturation and Th1 polarization. J Immunol 173: 307-313, 2004

30. Lotfi R, Herzog GI, DeMarco RA, Beer-Stolz D, Lee JJ, Rubartelli A, Schrezenmeier H and Lotze MT: Eosinophils oxidize damage-associated molecular pattern molecules derived from stressed cells. J Immunol 183: 5023-5031, 2009.

31. Liang Y, Hou C, Kong J, Wen H, Zheng X, Wu L, Huang H and Chen Y: HMGB1 binding to receptor for advanced glycation end products enhances inflammatory responses of human bronchial epithelial cells by activating p38 MAPK and ERK1/2. Mol Cell Biochem 405: 63-71, 2015.

32. Granucci F, Zanoni I, Feau S and Ricciardi-Castagnoli P: Dendritic cell regulation of immune responses: A new role for interleukin 2 at the intersection of innate and adaptive immunity. EMBO J 22: 2546-2551, 2003.

33. Kawai $\mathrm{T}$ and Akira S: The role of pattern-recognition receptors in innate immunity: Update on Toll-like receptors. Nat Immunol 11: 373-384, 2010.

34. MacLeod H and Wetzler LM: T cell activation by TLRs: A role for TLRs in the adaptive immune response. Sci STKE 2007: pe 48,2007
35. Lee KY, Ho SC, Lin HC, Lin SM, Liu CY, Huang CD, Wang CH, Chung KF and Kuo HP: Neutrophil-derived elastase induces TGF-betal secretion in human airway smooth muscle via NF-kappaB pathway. Am J Respir Cell Mol Biol 35: 407-414, 2006.

36. Mazarati A, Maroso M, Iori V, Vezzani A and Carli M High-mobility group box-1 impairs memory in mice through both Toll-like receptor 4 and receptor for advanced Glycation end products. Exp Neurol 232: 143-148, 2011.

37. Yu M, Wang H, Ding A, Golenbock DT, Latz E, Czura CJ, Fenton MJ, Tracey KJ and Yang H: HMGB1 signals through Toll-like receptor (TLR) 4 and TLR2. Shock 26: 174-179, 2006.

38. Yadav M, Jain S, Bhardwaj A, Nagpal R, Puniya M, Tomar R, Singh V, Parkash O, Prasad GB, Marotta F and Yadav H: Biological and medicinal properties of grapes and their bioactive constituents: An update. J Med Food 12: 473-484, 2009

39. Eo SH, Cho $\mathrm{H}$ and Kim SJ: Resveratrol inhibits nitric oxide-induced apoptosis via the NF-kappa B pathway in rabbit articular chondrocytes. Biomol Ther (Seoul) 21: 364-370, 2013.

40. Csaki C, Keshishzadeh N, Fischer K and Shakibaei M: Regulation of inflammation signalling by resveratrol in human chondrocytes in vitro. Biochem Pharmacol 75: 677-687, 2008.

41. Shakibaei M, John T, Seifarth C and Mobasheri A: Resveratrol inhibits IL-1 beta-induced stimulation of caspase- 3 and cleavage of PARP in human articular chondrocytes in vitro. Ann NY Acad Sci 1095: 554-563, 2007.

42. Elmali N, Esenkaya I, Harma A, Ertem K, Turkoz Y and Mizrak B: Effect of resveratrol in experimental osteoarthritis in rabbits. Inflamm Res 54: 158-162, 2005.

43. Im HJ, Li X, Chen D, Yan D, Kim J, Ellman MB, Stein GS, Cole B, Kc R, Cs-Szabo G and van Wijnen AJ: Biological effects of the plant-derived polyphenol resveratrol in human articular cartilage and chondrosarcoma cells. J Cell Physiol 227: 3488-3497, 2012.

44. Manna SK, Mukhopadhyay A and Aggarwal BB: Resveratrol suppresses TNF-induced activation of nuclear transcription factors NF-kappa B, activator protein-1 and apoptosis: Potential role of reactive oxygen intermediates and lipid peroxidation. J Immunol 164: 6509-6519, 2000.

45. Estrov Z, Shishodia S, Faderl S, Harris D, Van Q Kantarjian HM, Talpaz M and Aggarwal BB: Resveratrol blocks interleukin-1beta-induced activation of the nuclear transcription factor NF-kappaB, inhibits proliferation, causes S-phase arrest, and induces apoptosis of acute myeloid leukemia cells. Blood 102: 987-995, 2003.

46. Zhang C, Lin G, Wan W, Li X, Zeng B, Yang B and Huang C: Resveratrol, a polyphenol phytoalexin, protects cardiomyocytes against anoxia/reoxygenation injury via the TLR4/NF- $\kappa \mathrm{B}$ signaling pathway. Int J Mol Med 29: 557-563, 2012

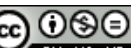

This work is licensed under a Creative Commons Attribution-NonCommercial-NoDerivatives 4.0 International (CC BY-NC-ND 4.0) License. 